\title{
Fe-Ti-Y (Iron-Titanium-Yttrium)
}

\section{Raghavan}

The two previous investigations of this ternary system by [1994Zen] and [1997Liu] reported isothermal sections at 500 and $600{ }^{\circ} \mathrm{C}$ respectively. These results were reviewed by [2001Rag] and [2000Rag]. Recently, [2009Gon] reported experimental results on this system at $1000{ }^{\circ} \mathrm{C}$ and presented a thermodynamic analysis.

\section{Binary Systems}

There are two intermediate phases in the Fe-Ti system: $\mathrm{Fe}_{2} \mathrm{Ti}$ (C14, $\mathrm{MgZn}_{2}$-type hexagonal) and $\mathrm{FeTi}$ (B2, CsCl-type cubic). The Fe-Y system is characterized by the presence of four compounds: $\mathrm{Fe}_{2} \mathrm{Y}\left(C 15, \mathrm{MgCu}_{2}-\right.$ type cubic), $\mathrm{Fe}_{3} \mathrm{Y}$ (Be $\mathrm{Be}_{3} \mathrm{Nb}$-type rhombohedral), $\mathrm{Fe}_{23} \mathrm{Y}_{6}$ $\left(\mathrm{Mn}_{23} \mathrm{Th}_{6}\right.$-type cubic) and $\mathrm{Fe}_{17} \mathrm{Y}_{2}\left(\mathrm{Ni}_{17} \mathrm{Th}_{2}\right.$-type hexagonal or $\mathrm{Th}_{2} \mathrm{Zn}_{17}$-type rhombohedral). In the Ti-Y system, there

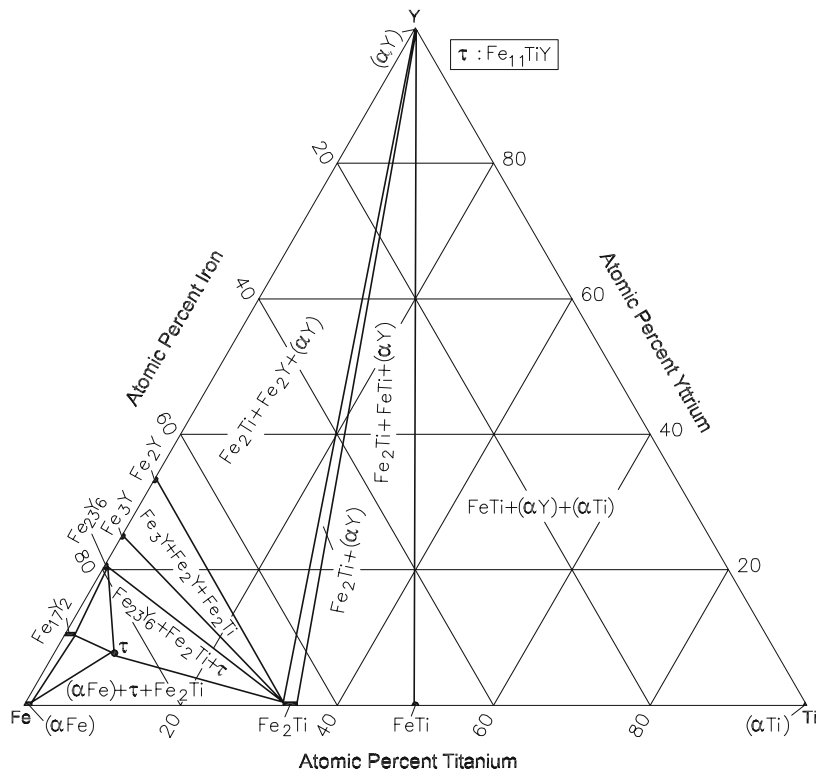

Fig. 1 Fe-Ti-Y isothermal section at $500{ }^{\circ} \mathrm{C}$ [1994Zen] are no intermediate phases. The terminal solid solubility is negligible.

\section{Ternary Phase Equilibria}

The study of [2009Gon] presents serious discrepancies. Quoting from their paper: "The experimental results show that $\mathrm{Fe}_{2} \mathrm{Ti}$ and $\mathrm{Fe}_{2} \mathrm{Y}$ form a continuous solid solution, namely, $\mathrm{Fe}_{2}$ (Y,Ti)". The previous results of [1994Zen] and [1997Liu] show little solubility between $\mathrm{Fe}_{2} \mathrm{Ti}$ and $\mathrm{Fe}_{2} \mathrm{Y}$. Moreover, they form different crystal structures. [2009Gon] modeled the "continuous solid solution" phase with two sub-lattices, with $\mathrm{Ti}$ and $\mathrm{Y}$ sharing sites in the second sublattice. They computed two isothermal sections at 600 and $1000{ }^{\circ} \mathrm{C}$. In none of the above sections, a continuous solid solution is seen. At $1000{ }^{\circ} \mathrm{C}$, a large liquid field is indicated at the $\mathrm{Ti}$ corner. $\mathrm{Ti}$ is solid at this temperature and shows little solubility for Y. In view of these serious anomalies, the results of [2009Gon] are not discussed further.

The isothermal section at $500{ }^{\circ} \mathrm{C}$ from the first investigation of this system by [1994Zen] (not presented in the earlier reviews) is redrawn in Fig.1.

\section{References}

1994Zen: L. Zeng, J. Li, X. Sun, and Y. Zhuang, Phase Equilibria in the Y-Ti-Fe System at $500{ }^{\circ} \mathrm{C}$, Z. Metallkd., 1994, 85(9), p 625-627

1997Liu: Z. Liu, Z. Jin, and C. Xia, 873 K Isothermal Section of Phase Diagram for Y-Fe-Ti Ternary System, Scr. Mater., 1997, 37(8), p 1129-1134

2000Rag: V. Raghavan, Fe-Ti-Y (Iron-Titanium-Yttrium), J. Phase Equilib., 2000, 21(5), p 467

2001Rag: V. Raghavan, Fe-Ti-Y (Iron-Titanium-Yttrium), J. Phase Equilib., 2001, 22(5), p 577

2009Gon: W.P. Gong, T.F. Chen, D.J. Li, and Y. Liu, Thermodynamic Investigation of Fe-Ti-Y Ternary System, Trans. Nonferrous Met. Soc. China, 2009, 19, p 199-204 